\title{
COMMENT
}

\section{Racial and ethnic disparities in adult COVID-19 and the future impact on child health}

\author{
Yarden S. Fraiman ${ }^{1,2}$, Jonathan S. Litt ${ }^{1,2,3,4}$, Jonathan M. Davis ${ }^{5}$, DeWayne M. Pursley ${ }^{1,2,3}$ and the Pediatric Policy Council \\ Pediatric Research (2021) 89:1052-1054; https://doi.org/10.1038/s41390-021-01377-x
}

\section{INTRODUCTION}

The coronavirus pandemic has highlighted U.S. racial and ethnic disparities across many domains. While health disparities have long existed, the coronavirus disease 2019 (COVID-19) pandemic, a 24-hour news cycle, and growing awareness of entrenched systemic racism in the United States have brought them into the forefront of national consciousness. While COVID-19associated disparities generally impact adults, the current pandemic has also exacerbated existing disparities in child health. We present an explanatory framework for how the disproportionate effects of adult COVID-19 among racial and ethnic minorities will lead to widening of current and future disparities among children and policy recommendations to curtail it.

For the purpose of this paper, we will refer to non-white Hispanic and Latinx communities as Hispanic and the Black and Hispanic communities together as communities of color. While this paper focuses on disparities among the Black and Hispanic communities, we recognize that many non-white racial and ethnic groups are disproportionately impacted by the pandemic. We believe many of the frameworks explained here are applicable to other racial and ethnic groups.

\section{ADULT CORONAVIRUS DISPARITIES}

Black and Hispanic communities are experiencing disproportionately higher rates of coronavirus infection, morbidity, and mortality. ${ }^{1}$ Underlying mechanisms that drive racial and ethnic disparities associated with COVID-19 are multifactorial. Disparities in high-risk health conditions (e.g., cardiovascular disease), longstanding residential segregation and crowding, poor access to healthy food, elevated levels of particulate pollution, and diminished access and equity in healthcare all contribute to disparities in COVID-19. ${ }^{1-3}$ Additionally, overrepresentation of Black and Hispanic adults in "essential" industries reduces their ability to practice social distancing or leverage work-from-home policies, thereby increasing high-risk and repeated exposure. ${ }^{2}$

It is important to note that the racial and ethnic disparities spotlighted by the pandemic are not the result of individual- or community-level decisions. ${ }^{2}$ Instead, the extreme pressure of the pandemic on the American healthcare system has further uncovered longstanding and deeply embedded structural inequities.

While over one million children have tested positive for the novel coronavirus, the rate of serious morbidity and mortality remains relatively low among children. ${ }^{3}$ However, the impact of the COVID-19 pandemic on adults will surely have an indelible impact on child health. Using a life course epidemiology framework, we propose three mechanisms by which the differential impact of the coronavirus pandemic on communities of color will widen existing disparities in child health. Life course epidemiology seeks to understand how early life exposures, biologic or social, inform health in childhood, adolescence, and adulthood. ${ }^{4}$ We anticipate that the coronavirus pandemic and its aftermath will have immediate, intermediate, and lasting effects on child health as outlined below.

\section{IMMEDIATE IMPACT TO PEDIATRIC HEALTH}

At the time of this writing, the American COVID-19 death toll exceeds a quarter million, representing an incredible loss of parents, caregivers, and community leaders. Black and Hispanic children will experience the death of a primary caregiver or close family member more frequently than white children because of disproportionate mortality in communities of color. The trauma children will experience associated with losing a loved one may be compounded by more widespread devastation they witness in their communities. Furthermore, the direct impact of COVID-19 on Black and Hispanic adults, coupled with a loss of community network and support, has led to disproportionate food, financial, and housing insecurity among these families., ${ }^{5,6}$ These childhood experiences of adversity, material hardship, and trauma impact child health. Furthermore, their emergence during "sensitive periods" will also impact the overall trajectory of health for Black and Hispanic children within the life course framework.

\section{INTERMEDIATE EFFECTS: THE TRANSMISSION OF SOCIOECONOMIC DISPARITIES TO CHILDREN}

In addition to the immediate emotional and socioeconomic impact of the coronavirus, the impact of the pandemic may persist even as the U.S. enters a stage of re-opening and economic recovery. Post-traumatic stress disorder and persistent serious emotional disturbance were reported among children who experienced community-impacting natural disasters, such as Hurricane Katrina. ${ }^{7,8}$ We anticipate that children experiencing trauma associated with the pandemic will similarly be at risk, especially Black and Hispanic children due to the higher impact of COVID-19 in communities of color.

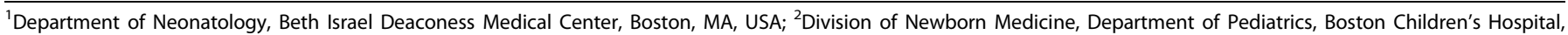

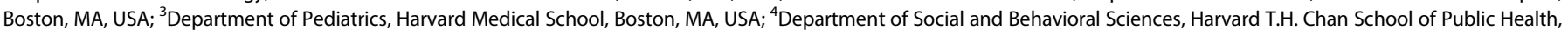
Boston, MA, USA and ${ }^{5}$ Department of Pediatrics, Tufts Children's Hospital, Boston, MA, USA

Correspondence: Yarden S. Fraiman (Yarden.Fraiman@childrens.harvard.edu)

Received: 21 December 2020 Accepted: 30 December 2020

Published online: 9 February 2021 
Furthermore, the economic impact of the pandemic on communities of color will be long-lasting. Black and Hispanic families are already experiencing more severe food and financial insecurity than white families as a result of the pandemic., Material hardship has detrimental impacts on child health and development over time. ${ }^{9}$ The disproportionate economic burden shouldered by communities of color will create further disparities between white and non-white children presently and in the future.

Finally, as schools have been shuttered, children across America are at risk of decreased long-term school readiness. School closures coupled with disparities in economic hardship, ability to work from home, difficulties with childcare, and internet access threaten to widen disparities in school achievement. ${ }^{5,6}$ As educational attainment is an important predictor of health, disparities in education during the pandemic will exacerbate existing racial and ethnic disparities in health across the life course. By understanding the "cumulative effects over time" mechanism of life course epidemiology, repeated exposures that are clustered on race, will lead to the accumulation of risk and subsequent deterioration of health for Black and Hispanic children over time. ${ }^{4}$

THE LASTING AND INTERGENERATIONAL IMPACT OF COVID-19 The differential impact of the coronavirus pandemic on communities of color will also lead to long-term disparities in health. COVID-19 may lead to increases in household dysfunction or adverse childhood experiences (ACEs). These, along with the increased risk of stress, trauma, material hardship, and adversity, will disproportionately impact communities of color that are most affected by the COVID-19 pandemic. Increased exposure to ACEs has been associated with the development of adult chronic diseases, such as cancer, cardiovascular disease, and depression. ${ }^{9}$ Additionally, a life course epidemiology framework illustrates how exposure to childhood adversity impacts health across generations. ${ }^{4,9}$ The differential exposure to ACEs, stress, trauma, and adversity among communities of color will lead to disparities in future adult health, will be amplified across the life course, and will be propagated across generations.

\section{A TIME TO ACT}

The life course epidemiology framework demonstrates how the impact of the coronavirus pandemic on adults, particularly in communities of color, will undoubtedly have lasting effects on pediatric health. Now more than ever we must affirm our commitment to pediatric health equity to prevent future widening of existing disparities, especially while the American public is reckoning with a history of systemic, structural racism and an increased awareness of disparities. Through research, advocacy, and clinical care, we propose the following to address current disparities and limit their future impact.

\section{RESEARCH}

Institutional policies should ensure that COVID-19-focused research considers racial and ethnic disparities. The NIH Revitalization Act of 1993 mandates that "minority groups" are included in research. Institutions should hold steadfast to their commitment to increasing scientific knowledge of severe acute respiratory syndrome coronavirus 2 (SARS-CoV-2) but with a lens toward equity-not only to "include" communities of color in scientific research (e.g., vaccine research) but importantly to highlight, explore, and understand disparities across the translational spectrum. Community-based participatory research partners with community stakeholders and can be effective for identifying the unique challenges affecting communities of color and addressing barriers to research participation. In addition, by recruiting Black and Hispanic researchers, medicine can begin to acknowledge-and right-centuries of institutional racism in the academy. A more diverse workforce fosters greater diversity of perspectives, interests, and research.

\section{ADVOCACY}

As local and federal governments propose budgets with an eye toward economic recovery, child health is primarily being left out of the conversation. It is crucial to advocate for child health today to ensure their future health. By securing funding for Federally Qualified Health Centers, safety-net hospitals, and the Title V Maternal and Child Health Services Block Grant Program, we can ensure that resources are secured for children to access the healthcare system and receive the care they need. As parents face losing employer-based health insurance, we must ensure that state child health insurance programs and provisions under expanded Medicaid are fully funded to reduce gaps in coverage. Furthermore, increasing funding to the Supplemental Nutrition Assistance Program and the Special Supplemental Nutrition Program for Women Infants and Children can provide a safeguard for families struggling with material hardships. It is imperative that all pediatricians advocate today for child health before the impact of coronavirus on adults creates greater inequities in pediatric health.

\section{CLINICAL CARE}

As pediatricians, our first duty is to treat the patient. Institutional policies standardizing screening for social determinants of health can improve early detection and referral to necessary services. ${ }^{10}$ Utilizing quality improvement frameworks for implementation with an equity lens can prevent bias and institutional norms from impacting inequitable screening and resource allocation. Finally, we must not forget the trauma that children and families, especially Black and Hispanic families, have experienced during the pandemic. Using a trauma-informed care approach can be the first step in creating positive change.

\section{CONCLUSION}

While the coronavirus pandemic has disproportionately impacted Black and Hispanic adults and generally spared children, the resulting disparities will be transmitted to children throughout the life course. It is our duty as pediatricians to focus on the future health of all children by advocating for policies that ensure meaningful research, secure the economic stability of healthcare systems committed to children's health, and promote dismantling structures that sustain disparities at the bedside and beyond.

\section{ACKNOWLEDGEMENTS}

Y.S.F. was supported by AHRQ T32HS000063 as part of the Harvard-wide Pediatric Health Services Research Fellowship Program.

\section{THE PEDIATRIC POLICY COUNCIL:}

Shetal Shah ${ }^{6}$, Jean L. Raphael ${ }^{7}$, Mona Patel ${ }^{7}$, Jonathan Davis ${ }^{8}$, DeWayne Pursley ${ }^{8}$, Tina Cheng $^{9}$, Michael Artman ${ }^{9}$, Joyce Javier ${ }^{10}$, Lois Lee ${ }^{10}$

${ }^{6}$ Pediatric Policy Council, Gainesville, USA; ${ }^{7} \mathrm{PPC}$ from the Academic Pediatric Association, Mclean, USA; ${ }^{8} \mathrm{PPC}$ from the American Pediatric Society, Itasca, USA ${ }^{9} \mathrm{PPC}$ from the Association of Medical School Pediatric Department Chairs, McLean, USA and ${ }^{10}$ Representative to the PPC from the Society for Pediatric Research, The Woodlands, USA

\section{AUTHOR CONTRIBUTIONS}

Y.S.F. conceived and drafted the manuscript. J.S.L., J.M.D., D.M.P., and members of the Pediatric Policy Council provided critical commentary, revision, and provided final approval of the version to be published. 
Racial and ethnic disparities in adult COVID-19 and the future impact on...

YS Fraiman et al.

1054

\section{ADDITIONAL INFORMATION}

Supplementary information The online version contains supplementary material available at https://doi.org/10.1038/s41390-021-01377-x.

Competing interests: The authors declare no competing interests.

Patient consent: Patient consent was not required.

Publisher's note Springer Nature remains neutral with regard to jurisdictional claims in published maps and institutional affiliations.

\section{REFERENCES}

1. Centers for Disease Control and Prevention (CDC). COVID-19 in racial and ethnic minority groups. https://www.hsdl.org/?view\&did=837299 (2020).

2. Williams, D. R. \& Cooper, L. A. COVID-19 and health equity-a new kind of "herd immunity". JAMA 323, 2478-2480 (2020).

3. AAP. Children and COVID-19: state-level data report. https://services.aap.org/en/ pages/2019-novel-coronavirus-covid-19-infections/children-and-covid-19-statelevel-data-report/ (2020).

4. Braveman, P. \& Barclay, C. Health disparities beginning in childhood: a life-course perspective. Pediatrics 124(Suppl 3), S163-S175 (2009).
5. Karpman, M., Gonzalez, D. \& Kenney, G. M. Parents are struggling to provide for their families during the pandemic material hardships greatest among lowincome, Black, and Hispanic parents. https://www.urban.org/sites/default/files/ publication/102254/parents-are-struggling-to-provide-for-their-families-duringthe-pandemic_1.pdf (2020).

6. Robert Wood Johnson Foundation. The impact of coronavirus on household, by race/ethnicity. https://www.rwjf.org/en/library/research/2020/09/the-impact-ofcoronavirus-on-households-across-america.html (2020).

7. Olteanu, A. et al. Persistence of mental health needs among children affected by Hurricane Katrina in New Orleans. Prehosp. Disaster Med. 26, 3-6 (2011).

8. Abramson, D. M., Park, Y. S., Stehling-Ariza, T. \& Redlener, I. Children as bellwethers of recovery: dysfunctional systems and the effects of parents, households, and neighborhoods on serious emotional disturbance in children after Hurricane Katrina. Disaster Med. Public Health Prep. 4(Suppl 1), S17-S27 (2010).

9. Shonkoff, J. P., Garner, A. S., Committee on Psychosocial Aspects of Child and Family Health, Committee on Early Childhood, Adoption, and Dependent Care \& Section on Developmental and Behavioral Pediatrics. The lifelong effects of early childhood adversity and toxic stress. Pediatrics 129, e232-e246 (2012).

10. Garg, A., Toy, S., Tripodis, Y., Silverstein, M. \& Freeman, E. Addressing social determinants of health at well child care visits: a cluster RCT. Pediatrics 135, e296-e304 (2015). 